\title{
Magnetic Amorphous Micro-Force Sensor
}

\author{
M. Nowicki ${ }^{a *}$, M. Kachniarz ${ }^{b}$, A. Juś ${ }^{a}$, T. Charubin ${ }^{a}$ And W. Radzikowska-Juśs ${ }^{c}$ \\ ${ }^{a}$ Institute of Metrology and Biomedical Engineering, Warsaw University of Technology, \\ sw. A. Boboli 8, 02-525 Warsaw, Poland \\ ${ }^{b}$ Industrial Research Institute for Automation and Measurements, Al. Jerozolimskie 202, 02-486 Warsaw, Poland \\ ${ }^{c}$ Faculty of Civil Engineering and Geodesy, Military University of Technology, \\ gen. S. Kaliskiego 2, 00-908 Warsaw, Poland
}

\begin{abstract}
In this paper the innovative method of microforce measurement based on air gap influence on magnetic circuits properties is presented. Magnetic ribbon core with air gap is put under transverse compressive stress perpendicular to the magnetic field direction generated by low-mass calibration weight. Change of the air gap induced by the force acting on the core causes change of its magnetic parameters. The possibility of utilization of various magnetic amorphous materials is investigated. Obtained results indicate a possibility of application of the developed sensor in microforce measurements.
\end{abstract}

DOI: 10.12693/APhysPolA.131.1180

PACS/topics: 07.10.Pz, 75.50.Kj

\section{Introduction}

Microforce measurements are very important in modern nanoscale technology. It is very complicated issue, requiring utilization of specialized measurement techniques. Typically, strain gauges are used, however they have limitations such as high sensitivity to environmental conditions (like temperature and humidity), they exhibit strain hysteresis (preloading of construction is required), they are disposable (after installation there is no possibility to demount them and reuse) and their installation is difficult, time-consuming and prone to errors [1]. Another commercially available technology are the piezoelectric force sensors. They have broad measurement range, are mechanically robust, and have high sensitivity. However, they are suitable only for dynamic load measurements, with the best available transducers allowing for quasi-static forces detection [2,3]. The most demanding force sensing applications are encountered in mass measurement, especially in analytic scales. Instead of simple sensor, they use complex magnetomechanical systems with feedback and optical zero detection $[4,5]$.

Among many experimental force sensors, magnetoelastic sensors are intensively developed $[6,7]$. They utilize toroidal cores made of amorphous alloys, where axial stress is acting on the core. Other solutions include magnetoelastic delay lines, perpendicularly loaded ring cores and lengthwise loaded amorphous ribbons [8-11]. They are however suitable for relatively high values of force such as encountered in civil engineering constructions monitoring, heavy industry etc. Typical forces measured by magnetoelastic transducers are in the $\mathrm{kN}$ range. There is still place for alternative approach for the $\mu \mathrm{N}$

*corresponding author; e-mail: m.nowicki@mchtr.pw.edu.pl measurement. This paper is filling this gap, with the new inductive force sensor, based on the high magnetic permeability, elasticity, and mechanical robustness of the amorphous alloy ribbon.

\section{Outline of the microforce sensor}

The developed amorphous microforce sensor is presented in Fig. 1. The magnetic air-gapped core is composed of single layer of amorphous alloy ribbon. It is mechanically formed into the $\mathrm{C}$ shape and mounted on the flat coil with the loose ends in the center of the coil. One of the loose ends acts as the cantilever, which is the force sensing element. The rest of the ribbon serves two purposes. It is both the magnetic circuit with the changing air gap and the mechanical spring opposing the measured force.

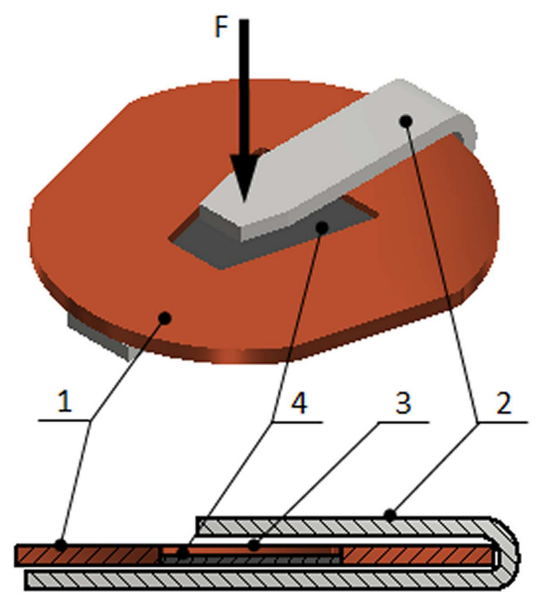

Fig. 1. Amorphous microforce sensor schematic. 1 coil, 2 - ribbon core, 3 - air gap, 4 - filler, $F$ applied force.

Under the axial load, the cantilever is slightly deformed and moves inside the coil, thus changing its inductance. 
When the load is kept in the $\mu \mathrm{N}$ range, the cantilever has less than $0.5 \mathrm{~mm}$ deformation and is in the elastic deformation region, returning to the original position. With greater loads, including pushing the ribbon fully inside the coil, the "zero" position may shift, the sensor is nonetheless still functional and far from plastic deformation. These effects can be avoided by filling the center of the coil with robust paramagnetic material, but still allowing for the $0.5 \mathrm{~mm}$ air gap. Overall, the design is very simple, the sensor is flat, and with the paramagnetic filler can withstand the forces outside the measurement range.

\section{Measurement methodology}

The measurement stand for investigation of functional properties of newly developed sensor is presented in Fig. 2. The sensor's coil was connected to precise MOTECH MT 4090 LCR meter for measurement of the inductance. The device was also supplying the coil of the sensor with voltage from $0.05 \mathrm{~V}$ to $1.00 \mathrm{~V}$. Sensor was placed on the zeroed weighing pan of the analytical balance RADWAG AS60/220/C/2 for precise measurement (with $0.1 \mu \mathrm{N}$ resolution) of the axial force acting upon it. The force was applied with the set of calibrated laboratory weights.

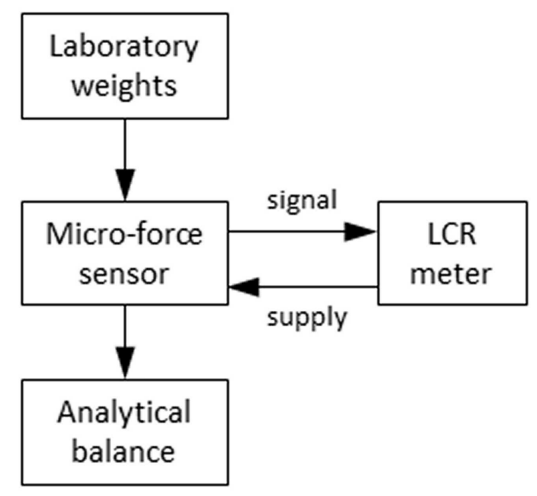

Fig. 2. The test stand for investigation of microforce sensor.

During the measurement the weights were placed on the sensor, and the resulting force was checked on the analytical balance. The mass of laboratory weights used for the experiment was within the range from $0 \mathrm{mg}$ to $100 \mathrm{mg}$, which resulted in force values from $0 \mu \mathrm{N}$ to about $980 \mu \mathrm{N}$.

\section{Experimental results}

For the investigation, three microforce sensors were developed, each utilizing magnetic amorphous ribbon of different chemical composition. Utilized amorphous materials were: $\mathrm{Fe}_{80} \mathrm{~B}_{11} \mathrm{Si}_{9}, \mathrm{Co}_{66} \mathrm{Fe}_{4} \mathrm{Ni}_{1} \mathrm{Si}_{15} \mathrm{~B}_{14}$ and $\mathrm{Fe}_{77} \mathrm{Cr}_{2} \mathrm{~B}_{16} \mathrm{Si}_{5}$. Each investigated sensor was tested with set of laboratory weights. Changes of inductance $\Delta L$ of the coil of sensor were measured. Supply voltage for the coils of the sensors was set to $0.25 \mathrm{~V}$. The frequency of supplying voltage was $1 \mathrm{kHz}$. Measurement results for all investigated amorphous ribbons are presented in Fig. 3.

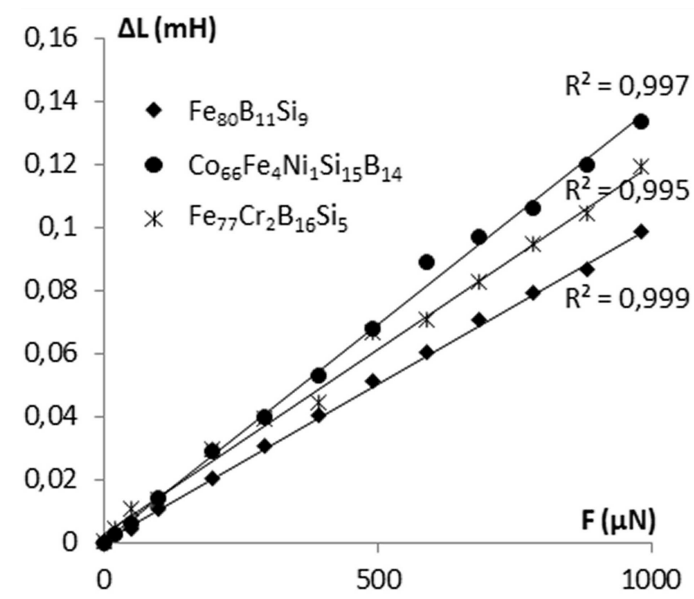

Fig. 3. Results of investigation of developed microforce sensors with different types of amorphous alloys, supply voltage $V_{S}=0.25 \mathrm{~V}$, frequency $f=1 \mathrm{kHz}$.

Obtained results present dependence of the measured inductance changes $\Delta L$ of the coil on force applied with the weights $F$. All presented characteristics are highly linear with determination coefficient $R^{2}$ over 0.990. Each investigated material used in sensor development exhibits different sensitivity, which is visible as a slope of obtained characteristic. On the basis of obtained characteristics sensitivity of each material was determined, which is presented in Table I.

TABLE I

Functional parameters of the investigated microforce sensors with different types of amorphous alloys.

\begin{tabular}{c|c|c}
\hline \hline Material & Sensitivity $[\mu \mathrm{H} / \mu \mathrm{N}]$ & Linear $R^{2}$ \\
\hline $\mathrm{Fe}_{80} \mathrm{~B}_{11} \mathrm{Si}_{9}$ & 0.0999 & 0.999 \\
$\mathrm{Co}_{66} \mathrm{Fe}_{4} \mathrm{Ni}_{1} \mathrm{Si}_{15} \mathrm{~B}_{14}$ & 0.1374 & 0.997 \\
$\mathrm{Fe}_{77} \mathrm{Cr}_{2} \mathrm{~B}_{16} \mathrm{Si}_{5}$ & 0.1171 & 0.995
\end{tabular}

For all investigated amorphous ribbons obtained sensitivity is relatively high and allows to measure microforces with satisfying resolution, which in the best case was equal to $10 \mu \mathrm{N}$. The highest sensitivity $0.1374 \mu \mathrm{H} / \mu \mathrm{N}$ was obtained for $\mathrm{Co}_{66} \mathrm{Fe}_{4} \mathrm{Ni}_{1} \mathrm{Si}_{15} \mathrm{~B}_{14}$ material. The highest linearity 0.999 was exhibited by $\mathrm{Fe}_{80} \mathrm{~B}_{11} \mathrm{Si}_{9}$ amorphous alloy.

Sensor with $\mathrm{Fe}_{80} \mathrm{~B}_{11} \mathrm{Si}_{9}$ material was additionally investigated with several different values of supplying voltage at the frequency $1 \mathrm{kHz}$ in order to determine optimal range of voltage for powering developed sensor. Results of this investigation are presented in Fig. 4. As it can be seen, for low values of supplying voltage $(0.05 \mathrm{~V}$ and $0.25 \mathrm{~V}$ ) obtained characteristics are similar and exhibit high linearity. For $1.00 \mathrm{~V}$ of supply voltage there is significant decrease in the slope of the characteristic. Linearity is also slightly lower. 


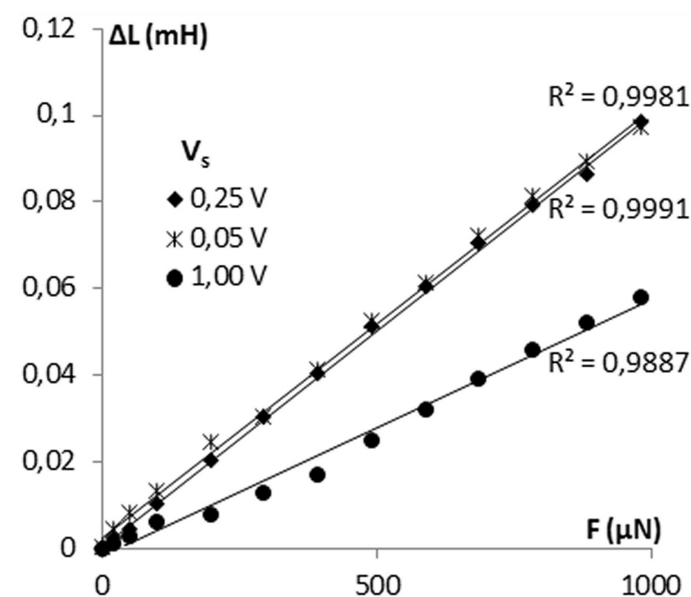

Fig. 4. Results of investigation of developed microforce sensor with $\mathrm{Fe}_{80} \mathrm{~B}_{11} \mathrm{Si}_{9}$ amorphous alloy for different values of supplying voltage $V_{s}$, frequency $f=1 \mathrm{kHz}$.

Again for each characteristic sensitivity was determined as a slope of the obtained line. The results are presented in Table II.

TABLE II

Functional parameters of the investigated microforce sensor with $\mathrm{Fe}_{80} \mathrm{~B}_{11} \mathrm{Si}_{9}$ amorphous alloy for different values of supplying voltage $V_{s}$.

\begin{tabular}{c|c|c}
\hline \hline Supply voltage $V_{s}[\mathrm{~V}]$ & Sensitivity $[\mu \mathrm{H} / \mu \mathrm{N}]$ & Linear $R^{2}$ \\
\hline 0.05 & 0.0986 & 0.998 \\
0.25 & 0.0999 & 0.998 \\
1.00 & 0.0592 & 0.989
\end{tabular}

Low values of supply voltage allows to obtain the highest sensitivity for given material. For $0.05 \mathrm{~V}$ and $0.25 \mathrm{~V}$ obtained values of sensitivity are similar. Increase of the supply voltage to $1.00 \mathrm{~V}$ results in significant decrease of the sensitivity.

\section{Conclusions}

Developed new microforce sensor presented in the paper is working correctly. It allows to measure very low forces with good functional parameters. Sensor exhibits satisfying sensitivity and linearity of the metrological characteristics. Different types of amorphous materials were investigated. Obtained results indicate that all tested alloys have good parameters, but it is possible to increase sensitivity by selection of proper chemical composition of the material. Performed investigation of the supply voltage influence on the properties of the sensor allows to conclude that low supplying voltages not exceeding $0.25 \mathrm{~V}$ are optimal.

Presented original idea of the force sensor is interesting from the point of view of precise force and mass measurements. Results obtained during performed tests are very promising. However, further investigation is necessary in order to select optimal chemical composition of amorphous alloy for the purpose of force sensing. Also further work to increase the resolution of the sensor is required.

\section{Acknowledgments}

This work was partially supported by the statutory founds of Institute of Metrology and Biomedical Engineering, Warsaw University of Technology (Poland).

\section{References}

[1] Handbook on Experimental Mechanics, Ed. A.S. Kobayashi, Prentice-Hall, Englewood Cliffs (NJ) 1993

[2] G. Gautschi, Piezoelectric Sensors, Springer, Berlin 2002, Ch. 5, p. 73.

[3] S.S. Rao, M. Sunar, Appl. Mech. Rev. 4, 113 (1994).

[4] S. Dabrowski, P. Bazydlo, R. Szewczyk, in: Progress in Automation, Robotics and Measuring Techniques, Eds. R. Szewczyk, C. Zielinski, M. Kaliczyńska, Springer, Berlin 2015, p. 49.

[5] P. Nowak, A. Juś, R. Szewczyk, R. Pijarski, M. Nowicki, W. Winiarski, in: Mechatronics - Ideas for Industrial Application, Eds. J. Awrejcewicz, R. Szewczyk, M. Trojnacki, M. Kaliczynska, Springer, Berlin 2015, p. 345.

[6] J. Salach, A. Bienkowski, R. Szewczyk, J. Magn. Magn. Mater. 316, 607 (2007).

[7] A. Bienkowski, R. Szewczyk, J. Salach, Acta Phys. Pol. A 118, 1008 (2010).

[8] A. Bienkowski, R. Szewczyk, T. Kulik, J. Ferenc, J. Salach, J. Magn. Magn. Mater. 304, 624 (2006).

[9] J. Bydzovsky, L. Kraus, P. Svec, M. Pasquale, J. Magn. Magn. Mater. 272-274, 1743 (2004).

[10] H. Chiriac, M. Pletea, E. Hristoforou, Mater. Sci. Eng. A 375-377, 1024 (2004).

[11] J.M. Barandiaran, J. Gutierrez, Sens. Actuat. A 59, 38 (1997). 